has been issued, which does not include the new class of drug. Comment: Mistaken-treatment with a new class of drug represents a new form of treatment and requires a fresh Certificate of Consent (Form 38).

Example O: The RMO obtains an independent second opinion from a consultant colleague who supports the plan to treat the non-consenting patient with ECT. The latter completes Form 39 (Certificate of Second Opinion) and treatment proceeds. Comment: Mistaken-a Certificate of Second Opinion can only be issued by a doctor appointed by the MHAC (under Section 121 (2)) on behalf of the Secretary of State.

\section{Use of Section 62 (Urgent Treatment)}

Example P: A detained patient is given ECT as an emergency (under Section 62). Section 62 then covers the remainder of the course and consent under Section 58 is not required. Comment: Mistaken-the MHAC appointed doctor should see the patient as soon as possible and decide whether treatment should continue with the issue of Form 39 (Certificate of Second Opinion).

Example Q: Section 62 sanctions the use of medication in emergency for any non-consenting detained patient. Comment: Mistaken-Section 62 does not cover patients held under Section 5 (4) (Nurse Holding Power); Section 5 (2); Section 4; Section 135 or Section 136. Common-law powers may apply here.

\section{Monitoring of Section 58 and Section 62}

Only two of the hospitals had developed procedures for centrally monitoring the issue of Form 38 Certificates and none were asking medical staff to positively inform them of the use of Section 62. Two-thirds of the hospitals had not developed a centrally organized flagging procedure to ensure that the RMOs were informed in good time of the three months' detention.

All views and opinions expressed in this article are those of the author and are not necessarily those of the Mental Health Act Commission.

\title{
Attitudes of British and Nigerian Teachers to Training African Psychiatrists in the UK*
}

John L. Cox, Senior Lecturer, Department of Psychiatry, Royal Edinburgh Hospital and O. O. FAmUYiwa, Senior Research Associate, Nuffield Psychology and Psychiatry Unit, Fleming Memorial Hospital, Newcastle upon Tyne

The increased fees for postgraduate trainees from overseas and their difficulty passing the MRCPsych examination have made some British teachers question whether Departments of Psychiatry should continue to provide training for such doctors. The change in the relationship between old and new Commonwealth countries, and the increased availability of postgraduate training in Nigeria, Kenya or Zimbabwe are other factors to be considered.

Since one of the authors (J.C.) had previously worked in Africa, and was now in Edinburgh, and the other (O.F.), having trained in Edinburgh, was a Lecturer in Nigeria, we had the opportunity to determine the attitudes of teachers towards training of overseas psychiatrists in Britain. In preparation for the African Psychiatry Association Conference a brief questionnaire was devised and sent to British and Nigerian tutors and Professors of Psychiatry. Specialist teachers were not included in the survey. The questionnaire was restricted to determining the attitudes to training sponsored overseas psychiatrists in Britain only, and not overseas psychiatrists working in a National Health Service

"This article is based on a paper read at the African Psychiatry Association meeting held in London in July 1983. post. The sponsored overseas psychiatrists were usually funded by their own Government, British Council, World Health Organization or the Association of Commonwealth Universities.

All teachers were asked whether a University Department of Psychiatry in Britain or teaching hospital had a responsibility to provide training for sponsored overseas psychiatrists, and to give reasons for their answer. Other items included an enquiry about the teacher's attitude to the suitability for an African trainee of the MRCPsych examination, and the possible benefits for a British trainee from working in Africa. British teachers were also asked how many sponsored overseas psychiatrists had been trained in the last five years.

The only biographical information obtained was the teachers' present post and the place of their first medical qualification.

The Nigerians received a questionnaire similar to that sent to UK teachers, but were also asked to describe any limitations of the postgraduate training in Nigeria.

\section{Attitudes of British teachers \\ Of the 201 British teachers who received our question-}


naire, 152 replied - a 75 per cent response rate. Of these 152 teachers, 134 fully completed the questionnaire and the results refer to this sample of respondents. Ninety-six UK teachers (72 per cent) were National Health Service Consultants, and 38 (28 per cent) held a University post. Most teachers qualified in Britain and 18 per cent were from overseas medical schools.

More than half (57 per cent) said that a UK teaching hospital had a 'definite' responsibility to train sponsored overseas trainees; a further 28 per cent indicating a 'probable' responsibility. The reasons commonly given for these replies included 'internationalism' (20 per cent), 'obligation' ( 31 per cent) and a few mentioned 'British tradition' or 'better facilities'.

Less than one-fifth said that such training should be in a sub-specialty of psychiatry, whilst a half thought a full professional training should be available. Only $\mathbf{4 0}$ per cent said that the MRCPsych was a suitable examination for an African psychiatrist; 13 per cent said it was 'probably' useful. Eighteen per cent believed it was not suitable at all. Most UK teachers ( 76 per cent) believed that a British trainee would benefit from working in Africa, and gave as their reasons increased knowledge about the relationship of culture to mental illness and enhancement of general education. Nine said the experience would enable the psychiatrist to provide an improved clinical service for immigrant communities to Britain.

Responses of those teachers qualified in an overseas medical school did not differ from teachers qualified in Britain. Likewise, no differences in the replies of teachers working in a university or in the NHS were found.

The Institute of Psychiatry had most sponsored overseas trainees (20 per year); Edinburgh usually having up to seven. Other centres (Cambridge, Liverpool, Nottingham, Leeds, Charing Cross, St George's Hospital and Leicester) rarely had more than two.

\section{Attitudes of Nigerian teachers}

Of the 33 Nigerian Consultants and Professors who received the questionnaire, 23 (70 per cent) replied. Most were postgraduate teachers and almost all had done part of their training in Britain.

Sixteen ( 73 per cent) of the 23 Nigerians said that train ing in Britain was relevant for work in Africa and a further five ( 22 per cent) said it was 'probably' relevant. However, 19 reported difficulty in applying some aspects of UK training to work in Africa, and questioned the applicability of certain aspects of psychotherapy. Of much interest was our finding that three-quarters of the Nigerians regarded their present postgraduate courses as deficient in certain respects. Deficiencies listed included inadequate clinical and research facilities ( 43 per cent), shortage of teaching personnel (43 per cent) and poor 'social service' facilities ( 8 per cent). The Nigerians believed that a Nigerian trainee would benefit by some training in Britain because of improved training facilities (60 per cent) and the opportunity to broaden professional horizons ( 30 per cent). Two said the trainee might develop a 'better attitude to work'.

Three-quarters believed that a British trainee would benefit from working in Africa by becoming more aware of the relationship between culture and mental illness, by learning how to work with limited resources, and by carrying out research that would only be possible in Africa.

\section{Conclusions}

Our main results were unexpected. Our experience had suggested that British teachers were less motivated to train African psychiatrists, and that Nigerians had less need to send trainees to Britain. It was clear, however, that most UK teachers still wished to train African psychiatrists and that many of the Nigerian teachers also desired that such training was available. The British teachers welcomed the international links fostered by such teaching contacts, and the Africans thought a British trainee who worked in Nigeria would obtain training not available in the UK.

It was less surprising perhaps that the MRCPsych examination was not regarded as always appropriate for an African psychiatrist. However, the finding that over one-half of British teachers wished a full professional training to be available for an overseas trainee suggested that their commitment was not to a short course of study only or restricted to a sub-specialty.

The majority of sponsored overseas trainees were at the Institute of Psychiatry in London and only a minority at other postgraduate centres. In Edinburgh, however, an analysis of MRCPsych results for Nigerians trained since 1976 showed that 13 of the 14 passed this examination, and that almost all were now working in Nigeria. It seemed likely that the training at different teaching centres in Britain varies considerably and that there are different entry requirements with regard to the PLAB examination, as well as the fee charged. Overseas trainees in Edinburgh, for example, being registered as part-time supervised postgraduate students in the university, are required to pass or to be exempt from the PLAB by the second year of their study.

We hope these results will contribute to the present discussion about training overseas psychiatrists. We think there is a need to use more appropriately the different training centres in Britain, so that the overseas trainee is then more likely to obtain value for money as well as receive the best that a UK training can offer. 